at swallowing (when the entroitus of the esophagus opens) the end of the instrument is delivered. I have used this electrode several hundred times with universal success and thus can recommend it as a most practical and satisfactory instrument.

228 East Nineteenth Street.

\section{A CASE OF INTERMITTENT LIMPING WITH SUGGESTIONS AS TO TREATMENT.}

\section{LEONARD W. ELY, M.D. NEW YORK.}

Under this and other names ${ }^{1}$ various authors have described a disease rather rare in this country, but occurring much more frequently in Russia. It consists of an obliterating endarteritis, and often ends in gangrene. The two characteristics are: First, the absence of pulsation in the arteries of the affected limb; and, second, a peculiar lameness accompanied by pain and by a sense of constriction in the calves. This pain comes on when the patient has walked a short distance, and subsides when he comes to a stop.

The case here reported is interesting for several reasons, principally, howcver, as showing the curative powers of rest. The patient was sten while under treatment, without the knowledge of his regular attendant, by one of the most eminent consultants in New York, and was told that he would never walk on his foot again. He had alreadiy lost one foot, and therefore was willing to carry out the long and tedious treatment prescribed for him. Lovett, in his excellent article on this disease, ${ }^{2}$ strongly advised rest as the one hope for recovery.

No examination was made of the foot that had been amputated, and little that is interesting can be learned of the patient's previous history from his former medical advisers, except the rather suggestive statement of one of them that "A. M. has lived a prettv swift life and has been a puzzle to all the doctors. The amount of albumin in his urine at times is shocking."

Patient.-A. M., aged 39 years, manager, married, and having two ehildren, was first seen Aug. 6, 1906, complaining of intermittent limping.

History.-In 1897 he was examined for life insurance and albumin was found in the urine. In 1898, patient had what appeared to be rheumatism in the heel, followed by a similar condition in the forearms, both of which were swollen, red and sore. Symptoms yielded to anti-rheumatic remedies. He denies syphilis.

In 1899 a peculiar form of limping appeared, a sense of constriction and pain in both calves appearing when the patient had walked a short distance, and disappearing when he rested. This was followed by swelling and redness along the right leg and foot. The patient went to bed for six weeks, took large doses of bicarbonate of soda, lemon juice and iron, and gradually recovered. There was a slight recurrence of these symptoms in 1900 and in 1901 , in both legs, but not severe enough to keep the patient from his business.

In June, 1902, an ulcer appeared under a corn on the fourth toe of the right foot, and refused to heal. One month later this ulcer was curetted. Then, on account of failure to heal, the toe was amputated. After this, for the same reason, there followed four more operations, the last in July, 1903-evi-

1. Intermittent claudication: đysbasia angiosclerotica, angina cruris : myasthenia paroxysmalis angiosclerotica, etc. The term in termittent claudication is misleading. The closure of the arterte is permanent, though the symptoms may intermit. Herein this disease appears to differ from Raynaud's disease and from erythromelalgia. Again, haynaud's disense is found most often in the upper extremities.

2. Jour. Am. Orthop. Assn., 1906 dently, first, an amputation of the metatarsal; second, an amputation from the big toe across the foot, removing the four outer toes; third, skin grafting; fourth, an amputation of the lower third of leg. The wound then healed promptly.

In 1904 and 1905 there was a slight recurrence of the trouble in the left leg, which seemed to be held in check by antirheumatic remedies. There has been no trouble in the right lower extremity since the amputation. Patient wears an artificial foot.

In May, 1906, the patient began to experience pain in the left foot and leg. The symptoms increased and interfered with the carrying on of his business.

Examination and Treatment.-Aug. 6, 1906, there was a slight redness and thickening about the internal malleolus and inner side of foot, which was sensitive to pressure. The diagrosis made was lymphangitis. Treatment consisted of wet dressings of aluminum acetate.

The symptoms grew better, then recurred. Mercurial ointment was applied, and although the patient presented no signs of syphilis, and said that he had undergone a rather thorough anti-syphilitic treatment some years before, he was put on iodid of potassium, and later had five injections of salicylate of mercury. Stockinette bandages were applied to the leg. On one or two occasions the patient kept his bed for a week or two and then scemed to become markedly better.

Following the inflammatory swelling about the ankle came a similar condition along the inner border of the gastrocnemius, a painful, thickened, indurated cord-evidently a phlebitis. Later, this phlebitis spread up to the knee, and then could be traced along the inner side of the thigh to the saphenous opening.

A consultation in the latter part of October, with Dr. Clarke, established the absence of pulsation in the posterior tibial and in the dorsalis pedis arteries. Pulsation in the left radial artery was smaller than in the right. The arteries throughout the body were apparently normal. There was no sclerosis.

The patient was then put to bed and was not allowed to leave it on any pretext.

Nov. 15, 1906.-Femoral artery pulsates somewhat. Pulsations can be felt in artery just internal to front of tibia. This pulsation ceases at a point half way down the leg. The patient wears stockinette bandages. The terminal joint of his left forefinger is numb and cold.

Jan. 10,1907 . The patient has been in bed since last note. Inflammatory symptoms bave disappeared. Will now go about apartment in wheeled chair.

January 22.-Leg in fairly good condition; circulation fair.

January 24.- Slight trace of albumin in morning urine. Albuminous food cut down.

February 10.- The patient walks about apartment to a moderate extent. The lower half of the leg and the foot are cold.

Jan. 1, 1908.-The patient remained in his apartment during the entire winter. As soon as all acute symptoms had disappeared, massage was begun, and for several months was continued. It was later replaced by vibratory massage. With the advent of warmer weather he began to go about, and gradwally resumed his accustomed manner of life, continuing however, the vibratory massage. He was instructed to avoid injury and exposure to cold.

February 13.-The leg is in better condition than it has ever been since first observation. Circulation is good in the toes; there is slight coldness of the foot. Pulsation can be felt as before half way down the leg, but no arterial pulsation can be felt below that point. Radials and temporals are normal. Patient says that he injured the skin on the back of his foot three months ago, but that the wound healed slowly. Vibration twice daily is being continued.

In spite of the improvement in the leg, the prognosis, if our ideas on the underlying pathologic process are correct, is very unfavorable. A wound is liable to put on the nutrition of the tissues a strain they are unable to bear, and the patient will lose this leg as he did the other. 